\title{
COMPARAÇÃO QUALI-QUANTITATIVA DA ARBORIZAÇÃO EM ESPAÇOS PÚBLICOS DA CIDADE DE ARAPIRACA-AL ${ }^{1}$
}

\author{
Rosineide Nascimento da Silva²; Marcos Antônio Silvestre Gomes ${ }^{3} 4$
}

\section{RESUMO}

O objetivo deste estudo foi analisar comparativamente a qualidade e a quantidade da arborização em seis espaços públicos situados nos bairros Cacimbas e Primavera e dois na área central da cidade de Arapiraca-Alagoas. Para a comparação foram consideradas a riqueza amostral, a abundância e o estado geral de conservação arbórea (satisfatório ou insatisfatório). As hipóteses testadas foram: I. A riqueza amostral de árvores difere entre os espaços públicos; II. A abundância de árvores difere entre os locais estudados; III. O estado geral da arborização varia com os locais. Para o levantamento foi aplicado um formulário quali-quantitativo e realizada a coleta de material botânico para identificação taxonômica através de bibliografia especializada. Foram registradas 424 árvores de 30 espécies, porém a riqueza amostral e a abundância apresentaram diferenças significativas entre os espaços públicos $(\mathrm{P}<0,001)$. Também verificaram-se diferenças entre os locais com arborização satisfatória e insatisfatória $(\mathrm{P}<0,001)$, resultante da ocorrência de formigas, fungos, cupins e outros, além da prática de poda nas árvores, injúrias/agressões mecânicas e conflitos com equipamentos urbanos. Os resultados indicam que a arborização tornou-se um elemento para usufruto de parcelas específicas da população, tendo em vista sua configuração socioespacial diferenciada no espaço urbano.

Palavras-chave: Estratificação arbórea; Áreas verdes urbanas; Fitossanidade.

\section{QUALI-QUANTITATIVE COMPARISON OF ARBORIZATION IN PUBLIC SPACES OF THE CITY OF ARAPIRACA-AL, BRAZIL}

\section{ABSTRACT}

The object of this study was to comparatively analyze the quality and quantity of trees in six public spaces in neighborhoods located Cacimbas and Primavera and two in the central city of Arapiraca, Alagoas. For comparison sample were considered wealth, abundance and general conservation tree (satisfactory or unsatisfactory). The hypotheses tested were: I. A richness of sample trees differs between public spaces, II. The abundance of trees differs between the sites studied, III. The general condition of the trees varies with the locals. To survey a form was applied quantitative and qualitative-held collection of botanical material for taxonomic identification through literature. We recorded 424 trees of 30 species, but the richness and abundance sample showed significant differences between the public spaces $(\mathrm{P}<0,001)$. Also there were differences between the local satisfactory arborization and unsatisfactory $(\mathrm{P}<0,001)$, resulting from the occurrence of ants, fungi, termites and others, besides the practice of pruning trees, mechanical injuries/conflicts with urban facilities. The results indicate that arborization has become an element of enjoyment to specific portions of the population, given its configuration sociospatial differentiation in urban space.

Keywords: Stratification trees; Green areas urbans; Phytossanitary.

\footnotetext{
${ }^{1}$ Parte dos dados referentes aos espaços públicos centrais de Arapiraca (Parque Municipal Ceci Cunha e a Área Verde Dom Constantino Luers) compõe o Trabalho de Conclusão de Curso do primeiro autor.

${ }_{2}^{2}$ Bióloga, Mestranda em Ecologia e Conservação, Universidade Federal de Sergipe - UFS, Avenida Marechal Rondon, s/n, Jardim Rosa Elze, 49100-000, São Cristóvão/SE. E-mail: rosineideg7@gmail.com.

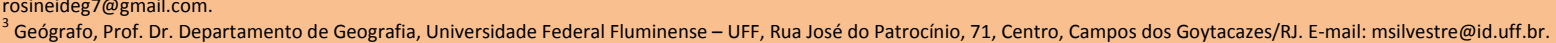

${ }^{4}$ Geografo, Prof. Dr. Departamento de Geografia, Universidade Fe 01.12 .2012 e aceito para publicą̧ão em 15.06 .2013
recerido
} 


\section{INTRODUÇÃO}

A problemática da arborização urbana desponta nas discussões do planejamento e gestão do espaço urbano devido à importância socioambiental que assume nas cidades. Entre as funções desempenhadas pela arborização, destacam-se: proteção do solo, da água, do ar; atenuação da temperatura e do clima; abrigo da fauna citadina; composição estético-paisagística; lazer/recreação; e valorização de determinadas parcelas do solo urbano (CAVALHEIRO e DEL PICCHIA, 1992; NUCCI, 2001; GOMES e AMORIM, 2003; YAMAMOTO et al., 2004; BRUN et al., 2007; FERNANDES, 2008).

As cidades representam um ambiente profundamente antropizado e, por isso a vegetação urbana é impactada diretamente pelas adversidades produzidas no âmbito das relações sociais cotidianas que alteram as características do meio natural.

Ao longo do século XX, especialmente, as cidades apresentaram rápida e crescente concentração populacional, que dentre outras consequências, contribuiu para a redução das áreas de vegetação. Nesse contexto, a arborização tem sido concebida, comumente, como mais uma infraestrutura urbana (TARNOWSKI e MOURA, 1991), sendo tratada nos espaços públicos, geralmente, como um elemento de valor estético-paisagístico, em detrimento das funções biológico-climáticas que desempenha.

A discussão sobre arborização urbana perpassa também pela necessidade de se considerar estratégias relativas à sua manutenção periódica com o intuito de minimizar os efeitos desencadeados, por exemplo, pela introdução e proliferação de agentes fitopagênicos, a prática de podas inadequadas, conflitos com equipamentos urbanos, homogeneização das espécies e impactos mecânicos (SILVA, 2012). Esses problemas, em geral, resultam da ausência ou insuficiência das ações públicas administrativas empregadas na arborização, sobretudo quando esta se encontra em locais de uso público, como praças e parques municipais.

Quanto ao aspecto quali-quantitativo da arborização que este estudo propõe comparar, Gonçalves e Rocha (2003) relatam que mais importante que quantificar a arborização de um determinado local é observar seu estado qualitativo, ou seja, apenas o levantamento quantitativo torna-se insatisfatório se não contemplar os parâmetros qualitativos (REZENDE e SANTOS, 2010).

Barros et al. (2010) citam a tendência de melhor adequação da arborização em parcelas das cidades ocupadas pela população de maior poder aquisitivo, pois como salienta Gomes (2009), as ações do poder público são desiguais no espaço urbano, em geral, privilegiando áreas consideradas "nobres" e as áreas centrais, como demonstrado em Ribeirão Preto - SP com a análise de parques urbanos.

Como ressaltam Barros et al. (2010) há ainda em número insuficiente relatos científicos sobre estudos comparativos da arborização, considerando-se setores urbanos com diferentes condições socioeconômicas. Neste intuito, este estudo foi realizado com o objetivo de avaliar comparativamente a qualidade e a quantidade da arborização encontrada em oito espaços públicos situados em diferentes bairros da cidade de Arapiraca-AL: Cacimbas, Centro, Novo Horizonte COMPARAÇÃo QUALI-QUANTITATIVA DA ARBORIZAÇÃO... 
e Primavera. Para esta análise, considerou-se a riqueza amostral (número de espécies), a abundância e o estado geral de conservação das árvores.

Os espaços públicos considerados neste estudo apresentam distintas características e se inserem de maneira diferenciada na malha urbana. Essas diferenças expressam-se nos significados para a população local, nas condições da infraestrutura, na localização, na apropriação de usos e nas relações com as variadas características socioeconômicas dos bairros em que se inserem. Tais espaços públicos se destacam em Arapiraca devido às potencialidades que apresentam, especialmente, para a composição da arborização.

Como forma de expor os aspectos gerais e as disparidades da arborização urbana nos espaços públicos de Arapiraca, foram testadas as seguintes hipóteses: I. A riqueza amostral de árvores difere entre os espaços públicos; II. A abundância de árvores difere entre os espaços e; III. O estado geral da arborização varia com os locais estudados.

\section{MATERIAL E MÉTODOS}

\section{Caracterização da área de estudo}

O município de Arapiraca, situado na Região Agreste do Estado de Alagoas, ocupa uma área de 356,18 $\mathrm{Km}^{2}$ e possui 214.006 habitantes (IBGE, 2010). Encontra-se a $264 \mathrm{~m}$ de altitude e a $136 \mathrm{~km}$ de distância de Maceió.

O município é caracterizado por temperaturas elevadas, com média anual de $25^{\circ} \mathrm{C}$, precipitação anual entre 750 e $1000 \mathrm{~mm}$ e regime de chuvas concentrado. Insere-se em uma região de clima tropical subúmido, com uma pluviosidade que varia ao longo dos anos (ARAPIRACA, 2006).

Quanto ao aspecto da arborização urbana, nota-se uma deficiência generalizada em Arapiraca. De acordo com o Dossiê Urbano Habitacional e Ambiental (ARAPIRACA, 2004), os bairros Centro e Novo Horizonte apresentam uma deficiência de arborização de 98,8\% e 95,3\%, respectivamente, embora sejam os bairros onde se localizam dois importantes espaços públicos da cidade: Parque Municipal Ceci Cunha e Área Verde Dom Constantino Luers. Esse dossiê também cita que o bairro Cacimbas apresenta uma carência de arborização de 94,1\%, enquanto o Primavera possui uma carência de 97,9\%.

O Parque Municipal Ceci Cunha é um dos locais públicos mais importantes quanto ao aspecto paisagístico e de lazer na cidade. A gênese deste espaço perpassa por uma história de ocultação e recriação de elementos da natureza desde a década de 1990, cujas etapas mais recentes foram concluídas nos anos de 2006 e 2007. Tornou-se ao longo dos anos um local desprivilegiado pela gestão pública, até o ano de 2006, quando foi ampliado. Embora apresente potencialidades socioambientais, as limitações deste parque referem-se, especialmente à regulação térmica, uma vez que a vegetação existente não garante o sombreamento, sobretudo nas etapas recentemente concluídas.

A Área Verde Dom Constantino Luers, localizada no bairro Novo Horizonte, integra uma região considerada "nobre" na cidade de Arapiraca e apresenta características que subsidiam diversos usos, como prática de atividades físicas, lazer contemplativo e recreação. Este espaço apresenta 
uma infraestrutura adequada, ampla arborização e bom aspecto estético-paisagístico, porém constitui um local para usufruto de um grupo específico de usuários em decorrência de sua localização privilegiada, cuja maioria da população do entorno possui alta renda.

Quanto às praças consideradas neste estudo, situadas nos bairros Primavera e Cacimbas, algumas destas podem ser localizadas pelas denominações das ruas que as interceptam, pois não apresentam nomes específicos. Assim, têm-se: uma praça entre as ruas Marechal Costa e Silva e José Honorato (Praça 1), bairro Primavera; e outra entre

\section{Coleta e análise de dados}

O levantamento dos dados ocorreu no período de setembro a novembro de 2010 e em setembro de 2012. Em cada espaço público foi realizado o registro das árvores através do preenchimento de um formulário quali-quantitativo, proposto por Silva Filho et al. (2002), adaptado e organizado para contemplar os objetivos deste estudo (Figura 1). Também foram coletadas amostras das árvores e fotografada a arborização com câmera digital.

No formulário foram registradas informações, como o nome e o endereço do espaço público; os aspectos fitossanitários de cada exemplar; a existência de determinados problemas/conflitos urbanos; e a ocorrência de podas nas árvores. Essas características, inicialmente, definiram o estado geral de cada indivíduo (ótimo, bom, regular e péssimo). Posteriormente, a arborização de cada espaço foi avaliada como satisfatória (soma das categorias ótimo e bom) ou insatisfatória (soma das categorias regular e péssimo).

A técnica de coleta e armazenamento do material botânico seguiu as descrições gerais de Mori et al. (1989). Esse material foi identificado no Laboratório de Biologia da Universidade Federal de as ruas Paulo Afonso e Olinda Magalhães (Praça 2), bairro Cacimbas. As demais praças denominam-se: Rosendo Vieira Lima e Pereira Magalhães, situadas no bairro Cacimbas; e João Pedro Aragão e Genuíno A. da Silva, situadas no bairro Primavera. Para Romão (2009), os bairros Cacimbas e Primavera estão entre os mais populosos de Arapiraca. Todavia, são bairros que se destacam não apenas pelo efetivo populacional, mas pela observação in loco das carências em infraestrutura urbana, como áreas de lazer para a população de baixa renda, arborização adequada, rede de esgotos, segurança pública, entre outros serviços.

Alagoas - Campus Arapiraca, através de consultas à bibliografia especializada (LORENZI et al., 2003; SOUZA e LORENZI, 2005; GONÇALVES e LORENZI, 2007; LORENZI, 2008; LORENZI, 2009;) e comparação morfológica com o auxílio de lupa, análises de exsicatas e fotografias. A nomenclatura baseou-se no Sistema de Classificação do APG II (SOUZA e LORENZI, 2005).

Com o registro da riqueza amostral e da abundância de árvores, bem como a observação do estado geral de conservação da arborização em cada espaço público, os dados foram plotados em planilhas do Microsoft Excel ${ }^{\circledR}$, sendo as análises estatísticas efetuadas no Programa R, versão 2.13.0 (R DEVELOPMENT CORE TEAM, 2011). Para as análises, foram considerados os modelos lineares generalizados (GLM’s), a Análise de Variância (ANOVA) e o teste Chi-quadrado $\left(\mathrm{X}^{2}\right)$ para distribuições não-nomais (Poisson). Assim, foram testadas as hipóteses formuladas.

COMPARAÇÃo QUALI-QUANTITATIVA DA ARBORIZAÇÃO... 
Figura 1. Formulário para análise quali-quantitativa da arborização. Fonte: Silva Filho (2002). Adaptado e organizado pelos autores

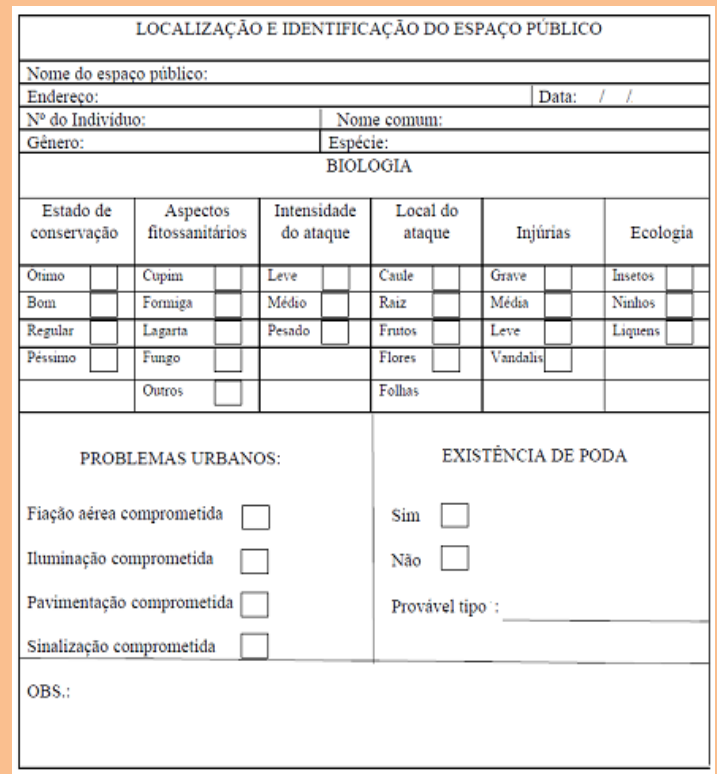

\section{RESULTADOS E DISCUSSÃO}

Dos espaços analisados no bairro Primavera, apenas a Praça Genuíno A. da Silva não apresentou nenhuma árvore, por isso, as análises se restringem aos demais espaços. Foram contabilizadas 424 árvores, pertencentes a 30 diferentes espécies, 30 gêneros e 11 famílias botânicas (Tabela 1). As famílias que contribuíram para a variedade

Tabela 1. Espécies arbóreas, nomes populares e famílias botânicas que ocorrem no Parque Municipal Ceci Cunha (PMCC), na Área Verde Dom Constantino Luers (AVDCL), na Praça Rosendo Vieira Lima (PRVL), na Praça Pereira Magalhães (PPM), na Praça 1 (bairro Cacimbas), na Praça João Pedro Aragão e na Praça 2 (bairro Primavera) em Arapiraca-AL

\begin{tabular}{|c|c|c|c|c|c|c|c|c|c|}
\hline $\begin{array}{l}\text { Espécies } \\
\text { arbóreas }\end{array}$ & $\begin{array}{c}\text { Nome } \\
\text { popular }\end{array}$ & Família & $\begin{array}{c}\text { PMC } \\
\text { C }\end{array}$ & $\begin{array}{c}\text { AVDC } \\
\text { L }\end{array}$ & $\begin{array}{c}\text { PRV } \\
\text { L }\end{array}$ & $\begin{array}{l}\mathbf{P P} \\
\mathbf{M}\end{array}$ & $\begin{array}{c}\text { Praça } \\
1\end{array}$ & PJPA & $\begin{array}{c}\text { Praça } \\
2\end{array}$ \\
\hline $\begin{array}{l}\text { Terminalia } \\
\text { catappa L. }\end{array}$ & Amendoeira & Combretaceae & $\bar{X}$ & - & - & $\bar{X}$ & - & - & - \\
\hline $\begin{array}{l}\text { Schinus } \\
\text { terebinthifolia }\end{array}$ & Aroeira & $\begin{array}{c}\text { Anacardiacea } \\
\text { e }\end{array}$ & $\mathrm{X}$ & $\mathrm{X}$ & - & - & - & - & - \\
\hline
\end{tabular}


Raddi

\begin{tabular}{|c|c|c|c|}
\hline $\begin{array}{l}\text { Erythrina } \\
\text { indica Lam. }\end{array}$ & $\begin{array}{c}\text { Brasileirinh } \\
\text { o }\end{array}$ & Fabaceae & $\mathrm{X}$ \\
\hline $\begin{array}{l}\text { Erythrina } \\
\text { velutina Willd }\end{array}$ & Mulungu & Fabaceae & $\mathrm{X}$ \\
\hline $\begin{array}{l}\text { Cassia fistula } \\
\text { L. }\end{array}$ & $\begin{array}{c}\text { Chuva-de- } \\
\text { ouro }\end{array}$ & Fabaceae & $\mathrm{X}$ \\
\hline $\begin{array}{l}\text { Hibiscus } \\
\text { tiliaceus L. }\end{array}$ & $\begin{array}{c}\text { Algodão-da- } \\
\text { praia }\end{array}$ & Malvaceae & - \\
\hline $\begin{array}{l}\text { Pachira } \\
\text { aquatica Aubl. }\end{array}$ & Monguba & Malvaceae & $\mathrm{X}$ \\
\hline $\begin{array}{l}\text { Tabebuia } \\
\text { aurea (Silva }\end{array}$ & $\begin{array}{c}\text { Craibeira/ip } \\
\hat{\text { ê }}\end{array}$ & Bignoniaceae & $\mathrm{X}$ \\
\hline
\end{tabular}

Manso) Benth.

\& Hook. f. ex

S. Moore

Ficus

benjamina L.

Delonix regia

(Bojer ex

Hook.) Raf.

Azadirachta

indica A. Juss.

Anadenanthera colubrina

(Vell.) Brenan var.

Enterolobium contortisiliquu m (Vell.)

Morong

Ceiba speciosa (A. St.-Hil.)

Ravenna

Chloroleucon

tortum (Mart.)

Pittier ex

Barneby \&

J.W. Grimes

Tecoma stans

(L.) Juss. ex

Kunth

Leucaena leucocephala

(Lam.) R. de

Wit

Adenanthera

pavonina L.

Pithecellobium

dulce (Roxb.)

Benth.

Sapindus

saponaria $\mathrm{L}$.

Tamarindus

indica L.

Senna siamea

Nim

Angico

Tamburil

Fabaceae

Paineira

Jurema

Bignonia-

amarela

Leucena

Carolina

Fabaceae

Ingá-doce

Fabaceae

Saboneteira

Tamarindo

Cássia

Malvaceae

Fabaceae

Fabaceae

Fabaceae

$$
\text { X }
$$$$
\text { X }
$$$$
\text { X }
$$

$$
\text { X }
$$

X

Meliaceae X

Fabaceae X

Fabaceae X


(Lam.) H.S.

Irwin \& R.C.

Barneby

Pritchardia

pacifica (Seem.

\& H. Wendl)

Tabebuia

impetiginosa

(Mart. Standl.)

Plumeria Alba

L.

Plumeria rubra

L.

$\begin{gathered}\text { Palmeira- } \\ \text { leque }\end{gathered}$
Arecaceae

Ipê-roxo Bignoniaceae X

_ Apocynaceae X

Jasmim- Apocynaceae $\mathrm{X}$

manga

Bauhinia Pata-de-vaca Fabaceae X

monandra Kurz

Bauhinia Pata-de-vaca Fabaceae X

purpurea L.

Thevetia

peruviana

(Pers.) K.

Schum

\section{Ravenala}

madagascarien

sis Sonn.

Caesalpinia pulcherrima

(L.) Sw.

Caesalpinia sp

Tabebuia $s p$

Roystonea $s p$

Archontophoen ix $s p$

Dypsis sp
Flamboianzi

nho

Árvore-do-

viajante

Musaceae

X

Apocynaceae $\quad \mathrm{X}$

$-$

Fabaceae

Ipê

Palmeira-

imperial

Bignoniaceae

Arecaceae

Palmeira

Arecaceae

X

Palmeira
Arecaceae

$\mathrm{X}$ 
Em sua maioria, as espécies registradas na arborização dos espaços públicos são tipicamente ornamentais, com destaque para as encontradas no Parque Municipal Ceci Cunha. Todavia, as espécies mais comuns entre os sete espaços públicos, foram Ficus benjamina L. (57,1\%) e Pachira aquatica Aubl. (42,8\%).

A maior ocorrência de $F$. benjamina não apenas pode ser constatada nos espaços de uso coletivo, mas na arborização geral da cidade de Arapiraca. Este fato, possivelmente deve-se à sua adaptabilidade, uma vez que pode ser cultivada em todo território brasileiro (LORENZI et al., 2003). A segunda colocada, P. aquatica, torna-se comum devido às características estruturais de sua copa, que proporciona amplo sombreamento (LORENZI, 2008). Esta espécie também foi citada por Silva
(2012) como de maior ocorrência nas principais praças situadas no centro de Arapiraca (Praças Luiz Pereira Lima, Deputado Marques da Silva e Manoel André).

Baseando-se no teste $\mathrm{X}^{2}$ tanto a riqueza amostral quanto a abundância de árvores apresentaram diferenças significativas entre os espaços públicos $(\mathrm{P}<0,001)$. Nos amplos espaços da área central de Arapiraca (bairros Centro e Novo Horizonte) concentraram-se as maiores riqueza e abundância de árvores, quando comparadas às encontradas nas pequenas praças dos demais bairros, ou seja, há uma distribuição irregular da arborização (Tabela 2).

Tabela 2. Dimensão territorial dos espaços públicos, riqueza amostral e abundância arbórea total em ArapiracaAL

\begin{tabular}{lccc}
\hline \multicolumn{1}{c}{ Espaços públicos } & $\begin{array}{c}\text { Dimensão } \\
\text { territorial } \\
\left(\mathbf{m}^{\mathbf{2}}\right)\end{array}$ & $\begin{array}{c}\text { Riqueza } \\
\text { arbórea } \\
\text { amostral }\end{array}$ & $\begin{array}{c}\text { Abundância } \\
\text { arbórea total }\end{array}$ \\
\hline Parque M. Ceci Cunha & 11.000 & 17 & 215 \\
Área Verde D. C. Luers & 13.230 & 10 & 173 \\
Praça Pereira Magalhães & 1.860 & 4 & 14 \\
Praça Rosendo V. Lima & 713 & 2 & 15 \\
Praça João P. Aragão & 229 & 1 & 2 \\
Praça Genuíno A. da Silva & 169 & - & - \\
Praça 1 (Primavera) & 298 & 1 & 4 \\
Praça 2 (Cacimbas) & 530 & 1 & \\
\hline
\end{tabular}

A existência de espaços públicos com diferenças significativas na riqueza amostral e na abundância de espécies arbóreas não reflete apenas diferenças espaciais na cidade, mas socioeconômicas. O Parque Municipal Ceci Cunha e a Área Verde Dom Constantino Luers apresentaram a maior riqueza amostral e abundância de árvores (28 espécies e 388 árvores) em comparação com o total registrado nas seis praças dos bairros Cacimbas e Primavera (8 espécies e 36 árvores).

A concentração da vegetação em áreas específicas da cidade, como as áreas centrais, justifica-se, muitas vezes, porque praças e parques tornam-se signos de bairros ou cidades, atrelados à imagem de grandes empreendimentos ou prefeitos empreendedores, como ocorre com o Parque 
Municipal Ceci Cunha, cuja implantação seguiu interesses político-administrativos específicos (SILVA e GOMES, 2010). Do mesmo modo, Gomes (2009) também discute a implantação do Parque Prefeito Luiz Roberto Jábali, em Ribeirão Preto-SP, como uma alegoria, um simulacro de natureza que caracterizou a gestão do prefeito que homenageia na sua nomenclatura.

A análise comparativa com outros estudos de distintas cidades do Brasil pode revelar especificidades das políticas locais e permitir, através da confrontação dos resultados, uma comparação que pode redundar em apontamentos importantes para a gestão destes espaços.

De modo geral, foi registrada uma riqueza de espécies e uma abundância arbórea nos sete espaços públicos de Arapiraca-AL superiores ao encontrado por Lima Neto et al. (2007) quando efetuaram o levantamento da arborização na Praça Olimpio Campos, situada no centro da cidade de Aracaju-SE (218 árvores e 26 espécies). No entanto, considerando-se a relação entre a abundância de árvores e a riqueza, verificou-se no estudo de Lima Neto et al. (2007) cerca de 8,4 árvores/espécie, enquanto o presente trabalho registrou uma relação de 14,1 árvores/espécie nos espaços de Arapiraca. Considere-se que a soma da área dos espaços públicos analisados em Arapiraca (total de 27.860 $\mathrm{m}^{2}$ ) é equivalente à área da Praça Olimpio Campos em Aracaju (27.713,37 m²).

Romani et al. (2012) constataram na Praça XV de Novembro, em Ribeirão Preto-SP, 42 espécies distribuídas por 161 indivíduos (3,8 árvores/espécie), enquanto Brito et al. (2012) verificaram, em praças públicas de Bom Jesus-PI, 19 espécies e 149 indivíduos (7,8 árvores/espécie). Mesmo não se considerando a proporcionalidade entre as áreas, importa ressaltar que esses resultados se mostraram divergentes dos encontrados no presente estudo, onde se notou uma tendência à homogeneização da arborização nos espaços públicos de Arapiraca.

A homogeneidade da arborização maximiza o risco de perdas causado pelo ataque eventual de algum tipo de fitopatógeno (LIMA NETO et al., 2007), situação que pode ser evitada através de um planejamento adequado da arborização. Essa homogeneidade também torna os espaços pouco harmoniosos e atrativos (YAMAMOTO et al., 2004; MACHADO et al., 2006; RODOLFO JÚNIOR et al., 2008).

Considerando-se 0 teste $\mathrm{X}^{2}$, também foram percebidas diferenças significativas entre os locais com arborização satisfatória e insatisfatória $(\mathrm{P}<0,001)$. A arborização do Parque Municipal Ceci Cunha e Área e da Verde Dom Constantino Luers foi considerada satisfatória (55,2\%), bem como a das praças dos demais bairros (55,6\%). De maneira geral, mesmo que a arborização dos espaços públicos tenha sido avaliada como satisfatória, o limite entre satisfatória e insatisfatória foi tênue porque enquanto os espaços da área central apresentaram 44,8\% de arborização insatisfatória, as praças dos bairros Cacimbas e Primavera apresentaram 44,4\%.

O estado geral da arborização resultou, dentre outros, do aspecto fitossanitário das árvores nos espaços da área central de Arapiraca, onde se constatou formigas, fungos, cupins, cochonilhas, minadores foliares, etc. A intensidade do ataque foi variada (Tabela 3). Os órgãos comumente atacados foram: caule $(89,2 \%)$, folhas $(12,6 \%)$ e raízes (0,2\%). Esses resultados indicam a necessidade de medidas eficientes de controle desses organismos, antes que ocasionem a morte da planta. 
Tabela 3. Aspectos fitossanitários e intensidades de ataques à arborização do Parque Municipal Ceci Cunha e Área Verde Dom Constantino Luers em Arapiraca-AL

\begin{tabular}{cc}
\hline \multicolumn{2}{c}{ Aspectos fitossanitários (\%) } \\
\hline Formigas & 78,1 \\
Fungos & 61,6 \\
Cupins & 4,6 \\
Lagartas & 0,5 \\
Outros & 9,5 \\
\hline Intensidades do ataque (\%) \\
\hline \multicolumn{2}{c}{ Leve } \\
Média & 69,1 \\
Grave & 19,6 \\
\hline
\end{tabular}

Dentre os organismos observados na arborização, também foram constatados líquens (23,2\%), insetos (12,9\%) e ninhos de aves (0,5\%). Os líquens são concebidos como bioindicadores de ambientes impactados, mas para Raven et al. (2001), esses organismos podem atuar como substrato para fungos parasitas. Portanto, considerar a presença dos líquens na arborização como um padrão de qualidade ambiental não deve ser suficiente para classificá-la como saudável. Por outro lado, a presença de ninhos de aves na arborização indica que os frutos de algumas espécies de árvores e as características de sua copa favorecem a nidificação (YAMAMOTO et al., 2004).

Outro aspecto observado foi a ocorrência de injúrias nas árvores, como os casos de vandalismo (27,3\%) representados por arranhões, pichações, sujeira, fixação de grampos ou pregos nas árvores etc. As intensidades dessas injúrias foram: leve (19,3\%), média $(10,3 \%)$ e grave $(0,2 \%)$ para os espaços da área central.

Os casos de vandalismos constantes nos espaços públicos reflete a necessidade de programas de educação ambiental em Arapiraca, não apenas no que se refere ao uso dos espaços coletivos, mas de quaisquer outros logradouros públicos. Uma das práticas mais comuns é a fixação de placas publicitárias, especialmente nos espaços centrais de maior visibilidade, e a fixação de pregos/grampos para ornamentação em épocas festivas. Entretanto, como a Prefeitura da Cidade de São Paulo (2005), não se recomenda, sob o ponto de vista fitossanitário, a utilização de enfeites e iluminação em ocasiões festivas.

Quanto aos conflitos da arborização com os equipamentos urbanos, percebeu-se no Parque Municipal Ceci Cunha Área e na Área Verde Dom Constantino Luers que 2,8\% das árvores conflitam com o sistema de iluminação, 0,5\% com a fiação elétrica e 0,8\% com imóveis construídos próximos (4,1\% de conflitos no total). Também foi verificada alta ocorrência de poda nas árvores (81,5\%), geralmente, buscando sua adequação às características do local onde se encontram (poda de formação) ou removendo ramos mortos e/ou doentes.

No que se refere à sanidade da arborização das praças dos bairros Cacimbas e Primavera foi observada a ocorrência de formigas, fungos, cupins e outros organismos. As intensidades do ataque COMPARAÇÃo QUALI-QUANTITATIVA DA ARBORIZAÇÃo... 
desses agentes foram, algumas vezes, leve e outras vezes média (Tabela 4). O principal órgão atacado foi o caule (80,6\%). Ainda foi registrada a existência de organismos como lagartos (8,3\%), líquens (33,3\%), moscas e abelhas (8,3\%) e ninhos de aves $(2,8 \%)$.
Quanto à ocorrência de injúrias, 58,3\% das árvores também sofrem com a fixação de pregos e placas publicitárias, amarrações com cordas, sujeira e arranhões. As intensidades dessas injúrias foram: leve $(44,4 \%)$ e média $(13,9 \%)$.

Tabela 4. Aspectos fitossanitários e intensidades de ataques à arborização das praças dos bairros Cacimbas e Primavera em Arapiraca-AL

\begin{tabular}{cc}
\hline \multicolumn{2}{c}{ Aspectos fitossanitários (\%) } \\
\hline Formigas & 66,7 \\
Fungos & 55,6 \\
Cupins & 8,3 \\
Outros & 2,8 \\
\hline Intensidades do ataque (\%) \\
\hline Leve & 47,2 \\
Média & 33,3 \\
\hline
\end{tabular}

No que se refere à adequação da arborização, notou-se que nas praças $13,9 \%$ das árvores conflitam com a pavimentação, 5,6\% com a sinalização e 2,8\% com o sistema de iluminação (22,3\% de conflitos no total). Todavia, foi percebido que $86,1 \%$ das árvores sofrem poda, especialmente, a do tipo formação.

Foi observada uma maior ocorrência de conflitos da arborização nos espaços dos bairros Cacimbas e Primavera do que nos da área central. Um problema comum aos espaços públicos foi o conflito da arborização com o sistema de iluminação. Como destacam Mota e Almeida (2011), os principais transtornos gerados por uma arborização sem manejo adequado são representados pelo rompimento de fios de alta-tensão, obstruções em redes de esgoto, acidentes com pedestres, veículos ou edificações, entre outros.

A existência de poucos conflitos entre a arborização e as estruturas urbanas nos espaços centrais pode indicar que o poder público dispõe de maior cuidado com estes locais, se comparada com a dos demais bairros, por exemplo. No entanto, a arborização dos locais estudados apresentou elevados indícios de podação. É comum a poda ser realizada por pessoas não especializadas, o que aumenta os riscos de comprometimento da sanidade da arborização urbana.

Para Bortoleto (2004) podas mal conduzidas acentuam os casos de árvores em início ou final de declínio, descaracterizando o componente arbóreo. A poda em épocas inviáveis, como no verão, aumenta a presença de fungos devido a não cicatrização das árvores, associada a fatores ambientais (elevadas temperatura e umidade). Dessa forma, a poda causa danos muitas vezes irreversíveis à árvore, pois, em geral, os executores mutilam os indivíduos, evidenciando um manejo arbóreo inadequado (LIMA NETO et al., 2007). É preciso um conhecimento básico da anatomia e Rosineide Nascimento da Silva e Marcos Antônio Silvestre Gomes 
fisiologia das espécies arbóreas, pois são poucas as ocasiões em que a poda contribui com o desenvolvimento do vegetal.

Considerando os aspectos mais amplos desta discussão, os resultados do trabalho permitem inferir que a arborização urbana comumente se apresenta como um elemento para usufruto de parcelas específicas da população, uma vez que distribui-se de modo diferenciado no espaço urbano de Arapiraca, notadamente em praças e parques. Apesar de a arborização dos espaços analisados ter sido considerada satisfatória, não se verificou uma tendência de adequação dessa arborização nos espaços públicos que não integram a área central de Arapiraca, especialmente quando se considera o número de espécies e a quantidade de indivíduos nas praças dos demais bairros.

\section{CONSIDERAÇÕES FINAIS}

A concentração da arborização em locais de melhor infraestrutura, como os bairros Centro e Novo Horizonte, demonstra que uma expressiva parcela da população encontra-se destituída do direito de usufruir cotidianamente dos espaços coletivos melhor arborizados, com cuidados estéticopaisagísticos e com melhor infraestrutura. Da mesma forma, este fato evidencia as ações desiguais do poder público no espaço urbano. Quando analisada comparativamente, a arborização dos espaços públicos da área central e aquela dos bairros Cacimbas e Primavera elucida importantes diferenças tanto em qualidade quanto em quantidade.

Através da metodologia utilizada, que possibilitou a construção de um quadro amostral e de um diagnóstico da arborização em diferentes bairros da cidade de Arapiraca, como resposta à problemática analisada, recomenda-se aos órgãos públicos municipais a criação de um Plano de Manejo e de Monitoramento que contemple tanto a arborização viária quanto aquela presente nos espaços públicos. Também, destaca-se a viabilidade de se instituir um Departamento de Áreas Verdes no interior da Secretaria de Meio Ambiente do município, com o intuito de ampliar o efetivo arbóreo, o cuidado fitossanitário, a variabilidade das espécies e a distribuição regular das árvores nos locais públicos de Arapiraca, independentemente dos bairros onde se situem ou dos interesses político-eleitoreiros, comumente observados.

\section{AGRADECIMENTOS}

Ao professor Henrique Costa Hermenegildo da Silva pela identificação de algumas espécies e à Carla Caroline Felício Pessoa pelo auxílio na coleta do material botânico e produção fotográfica, ambos da Universidade Federal de Alagoas (UFAL); à
Daiane Rafaela Freitas da Silva e a Luiz Carlos Tenório (UFAL) pelo auxílio na medição de alguns espaços públicos; e à Janimara Marques da Silva (UFAL) pelas sugestões e correção da primeira versão do texto. 
ARAPIRACA. Dossiê urbano habitacional e ambiental do Município de Arapiraca - AL. Cooperativa de Trabalhadores Ambientalistas. Maceió, 2004. 257p.

ARAPIRACA. Relatório das características ambientais do município de Arapiraca - AL. Secretaria Municipal de Desenvolvimento Urbano e Meio Ambiente. Universidade Estadual de Alagoas. Arapiraca, 2006. 99p.

BARROS, E. F. S.; GUILHERME, F. A. G.; CARVALHO, R. S. Arborização urbana em quadras de diferentes padrões construtivos na cidade de Jataí. Revista Árvore, v.34, n.2, p. 287-295, 2010.

BORTOLETO, S. Inventário quali-quantitativo da arborização viária da Estância de Águas de São Pedro SP. 2004. 98f. Dissertação (Mestrado em Agronomia: Fitotecnia). Escola Superior de Agricultura Luiz Queiroz. Universidade de São Paulo, Piracicaba, 2004.

BRITO, D. R. S. Diagnóstico da arborização das praças públicas no município de Bom Jesus, Piauí. Scientia Plena, v.8, n.4, p. 1-6, 2012.

BRUN, F. G. K.; LINK, D.; BRUN, E. J. O emprego da arborização na manutenção da biodiversidade de fauna em áreas urbanas. Revista da Sociedade Brasileira de Arborização Urbana, v.2, n.1, p. 117-127, 2007.

CAVALHEIRO, F.; DEL PICCHIA, P. C. D. Áreas verdes: conceitos, objetivos e diretrizes para o planejamento. In: CONGRESSO BRASILEIRO SOBRE ARBORIZAÇÃO URBANA E IV ENCONTRO NACIONAL SOBRE ARBORIZAÇÃO URBANA, 1., 1992, Vitória. Anais... Vitória, 1992, p. 29-38.

FERNANDES, A. M. V. O reencantamento (mercadológico) pela natureza e a segregação socioespacial na APA de Sousas e Joaquim Egídio (Campinas/SP). In: ENCONTRO NACIONAL DE GEÓGRAFOS: O ESPAÇO NÃO PÁRA. POR UMA AGB EM MOVIMENTO, 15., São Paulo. Anais... São Paulo, 2008. CD ROM.

GOMES, M. A. S. Parques urbanos de Ribeirão Preto - SP: na produção do espaço, o espetáculo da natureza. 2009. Tese (Doutorado em Geografia). Universidade Estadual de Campinas: IGE. São Paulo, 2009.

GOMES, M. A. S.; AMORIM, M. C. C. T. Arborização e conforto térmico no espaço urbano: estudo de caso nas praças públicas de Presidente Prudente - SP. Revista Caminhos de Geografia, v.7, n.10, p. 94-106, 2003.

GONÇALVES, E. G.; LORENZI, H. Morfologia vegetal: organografia e dicionário ilustrado de morfologia das plantas vasculares. Nova Odessa: Instituto Plantarum, 2007. 306p.

GONÇALVES, S.; ROCHA, F. T. Caracterização da arborização urbana do bairro de Vila Maria Baixa. Revista Científica Conscientia e Saúde, v.2, p. 67-75, 2003.

INSTITUTO BRASILEIRO DE GEOGRAFIA E ESTATÍSTICA (IBGE). Cidades. Disponível em: <http://www.ibge.gov.br>. Acesso em: 24 Ago. 2012.

LIMA NETO, E. M. et al. Análise das áreas verdes das praças do bairro Centro e principais avenidas da cidade de Aracaju - SE. Revista da Sociedade Brasileira de Arborização Urbana, v. 2, n. 1, p. 17-33, 2007.

LORENZI, H. Árvores brasileiras: manual de identificação e cultivo de plantas arbóreas nativas do Brasil. 5. ed. Nova Odessa: Instituto Plantarum, 2008. 384p.

LORENZI, H. Árvores brasileiras: manual de identificação e cultivo de plantas arbóreas nativas do Brasil. 3. ed. Nova Odessa: Instituto Plantarum, 2009. 384p.

LORENZI, H. et al. Árvores exóticas no Brasil: madeireiras, ornamentais e aromáticas. Nova Odessa: Instituto Plantarum, 2003. 368p. 
MACHADO, R. R. B. et al. Árvores nativas para arborização de Teresina - Piauí. Revista da Sociedade Brasileira de Arborização Urbana, v.1, n.1, p. 10-18, 2006.

MORI, S. et al. Manual de manejo do herbário fanerogâmico. Ilhéus: CEPLAC, 1989. 104p.

MOTA, M. P.; ALMEIDA, L. F. R. Características da arborização na região central do município de Coxim, MS. Revista da Sociedade Brasileira de Arborização Urbana, Piracicaba, v. 6, n. 1, p. 01-24, 2011.

NUCCI, J. C. Qualidade ambiental e adensamento urbano. São Paulo: Humanitas/FAPESP, 2001. 236p.

PREFEITURA DA CIDADE DE SÃO PAULO. Manual técnico de arborização urbana. 2. ed. Disponível em: $<$ http://www.arvoresbrasil.com.br>. Acesso em: 14 Set. 2012.

R DEVELOPMENT CORE TEAM. 2011. R: a language and environment for statistical computing. Versão 2.13.0. R Foundation for Statistical Computing, Vienna, Austria. ISBN 3-900051-07-0. Disponível em: $<$ http://www.r-roject.org>. Acesso em: 13 Abril 2011.

RAVEN, P. H.; EVERT, R. F.; EICHHORN, S. E. Fungos. In. Biologia vegetal. 7. ed. Rio de Janeiro: Guanabara Koogan, 2010, p. 277-312.

REZENDE, T. M.; SANTOS, D. G. Avaliação quali-quantitativa da arborização das praças do bairro Jaraguá, Uberlândia - MG. Revista da Sociedade Brasileira de Arborização Urbana, v.5, n.2, p. 139-157, 2010.

RODOLFO JÚNIOR, F. et al. Análise da arborização urbana em bairros da cidade de Pombal no Estado da Paraíba. Revista da Sociedade Brasileira de Arborização Urbana, v.3, n.4, p. 3-19, 2008.

ROMANI, G. N. et al. Análise quali-quantitativa da arborização na Praça XV de Novembro em Ribeirão Preto SP, Brasil. Revista Árvore, v.36, n.3, p. 479-487, 2012.

ROMÃO, S. R. L. Plano de saúde ambiental - Arapiraca/Alagoas: uma experiência de trabalho em rede. In: SEMINÁRIO INTERNACIONAL "EXPERIÊNCIAS DE AGENDAS 21: OS DESAFIOS DO NOSSO TEMPO”, 1., 2009, Ponta Grossa. Anais... Ponta Grossa, 2009. Disponível em: <http://www.eventos.uepg.br>. Acesso em: 24 Ago. 2012.

SILVA FILHO, D. F. et al. Banco de dados relacional para cadastro, avaliação e manejo da arborização em vias públicas. Revista Árvore, v.26, n.5, p. 629-642, 2002.

SILVA, R. N. Caracterização e análise quali-quantitativa da arborização em praças da área central da cidade de Arapiraca, AL. Revista da Sociedade Brasileira de Arborização Urbana, v.7, n.2, p. 102-115, 2012.

SILVA, R. N.; GOMES, M. A. S. Parques urbanos em Alagoas: caracterização e análise no âmbito da produção do espaço. Revista Percurso, v.2, n.1, p. 107-133, 2010.

SOUZA V. C.; LORENZI H. Botânica sistemática: guia ilustrado para identificação das famílias de angiospermas da flora brasileira, baseado em APG II. Nova Odessa: Instituto Plantarum, 2005.

TARNOWSKI, L. C.; MOURA, R. O espaço do meio ambiente urbano no discurso ecológico. In: ENCONTRO NACIONAL DE ESTUDOS SOBRE O MEIO AMBIENTE, 3., 1991, Londrina. Anais... Londrina: UEL/NEMA, 1991, p. 379-391.

YAMAMOTO, M. A. et al. Árvores Urbanas. Piracicaba, 2004. 18p. Disponível em: <http://lmq.esalq.usp.br>. Acesso em: 17 jan. 2011. 